\title{
Stress and Strain Behaviors of Mg Alloy AZ31 in Plane Strain Compression*
}

\author{
Ikuo YARITA**, Takashi NAOI*** and Tsuyoshi HASHIZUME***
}

\begin{abstract}
Most of magnesium alloy products are manufactured by die casting or thixo-molding processes. However, there is extremely little use of the products by metal forming due to high resisting plastic deformation in normal temperature and their expensive cost. In this study, to make clear the plastic deformability, stress and strain behaviors of $\mathrm{Mg}$ alloy AZ31 hot rolled sheet in plane strain compression in the temperature from $20^{\circ} \mathrm{C}$ to $250^{\circ} \mathrm{C}$ have been discussed. Tension test and plane strain compression test have been performed to obtain the equivalent stress and equivalent plastic strain relations. The plane strain compression tests with some lubricants have been performed, and the effect of friction between die and deforming material on plastic deformation behaviors has been investigated by the elastic-plastic finite element analysis. Optical microstructures of deformed materials are also observed.
\end{abstract}

Key Words: Magnesium Alloy AZ31, Plastic Deformation, Stress and Strain, Plane Strain Compression

\section{Introduction}

There are many demands for magnesium alloys to employ the automotive parts and electric products due to $\mathrm{Mg}$ alloys have many profitable properties such as small specific gravity, high specific strength, vibration absorption and EMI shielding. However, most of Mg alloy products are manufactured by die casting or thixo-molding processes. There is extremely a little use of the products by metal forming except for electronic machine part's cases, which caused from high resisting plastic deformation in the normal temperature, poor anti-corrosiveness ${ }^{(1)}$ and their expensive cost. To expand the products by metal forming, the efficient rolling technology to obtain thin sheet products having high mechanical properties and surface quality is required. Thus, the optimum sheet forming technology should be established. However, a few technical information of metal forming as rolling and sheet forming for $\mathrm{Mg}$ alloys $^{(2)}-(5)$ has been described.

In this study, stress and strain behaviors of $\mathrm{Mg}$ alloy AZ31 hot-rolled sheet in plane strain compression in the

* Received 3rd June, 2005 (No. 05-4099)

** Department of Mechanical Science \& Engineerring, Chiba Institute of Technology, 2-17-1 Tsudanuma, Narashino, Chiba 275-0016, Japan.

E-mail: yarita.ikuo@it-chiba.ac.jp

*** Graduate Student, Chiba Institute of Technology, 2-17-1 Tsudanuma, Narashino, Chiba 275-0016, Japan temperature from $20^{\circ} \mathrm{C}$ to $250^{\circ} \mathrm{C}$ have been discussed ${ }^{(6),(7)}$ to make clear the plastic deformability. Tension test and plane strain compression test have been performed to obtain the equivalent stress and equivalent plastic strain relations. The plane strain compression tests with some lubricants have been performed, and the effects of friction between die and deforming material on plastic deformation behaviors are investigated by the elastic-plastic finite element analysis.

\section{Stress and Strain Behaviors}

\subsection{Specimen}

Hot-rolled sheets of magnesium alloy AZ31 have been employed. Table 1 shows chemical compositions, and Fig. 1 shows microstructure of the sheet for tensile and plane strain compression tests. Mean grain size is about $11 \mu \mathrm{m}$.

\subsection{Tensile test}

Uni-axial tensile tests have been conducted under the conditions in the temperature from the normal temperature $\left(20^{\circ} \mathrm{C}\right)$ to $250^{\circ} \mathrm{C}$, and the strain rate from $4 \times 10^{-4}$ to $4 \times$ $10^{-2}$. Figures 2 and 3 show experiment results for effects

Table 1 Chemical compositions of AZ31 sheets(mass\%)

\begin{tabular}{|c|c|c|c|c|c|c|}
\hline $\mathrm{Al}$ & $\mathrm{Zn}$ & $\mathrm{Mn}$ & $\mathrm{Fe}$ & $\mathrm{Si}$ & $\mathrm{Cu}$ & $\mathrm{Mg}$ \\
\hline $\begin{array}{c}2.5 \\
\sim 3.5\end{array}$ & $\begin{array}{c}0.6 \\
\sim 1.4\end{array}$ & $\begin{array}{c}0.20 \\
\sim 1.0\end{array}$ & 0.005 & 0.10 & 0.005 & Bal. \\
\hline
\end{tabular}




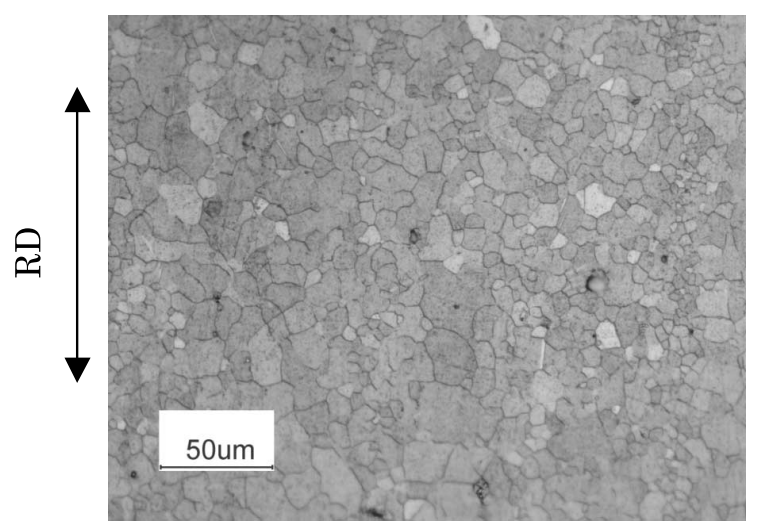

Fig. 1 Microstructure of hot-rolled AZ31 sheet

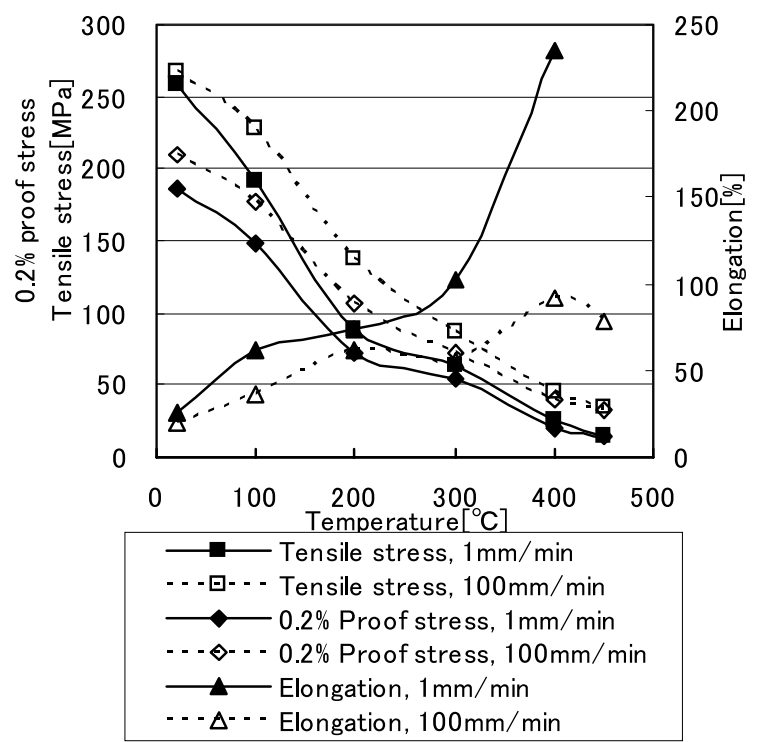

Fig. 2 Effect of temperature on $0.2 \%$ proof stress, tensile strength and elongation

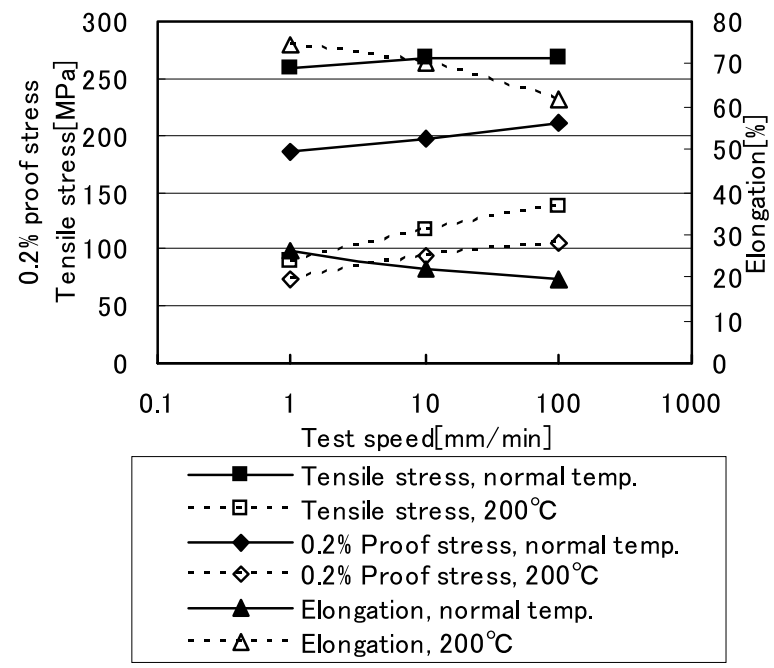

Fig. 3 Effect of test speed on $0.2 \%$ proof stress, tensile strength and elongation

of temperature and test speed (strain rate) on $0.2 \%$ proof stress, tensile strength and elongation respectively.

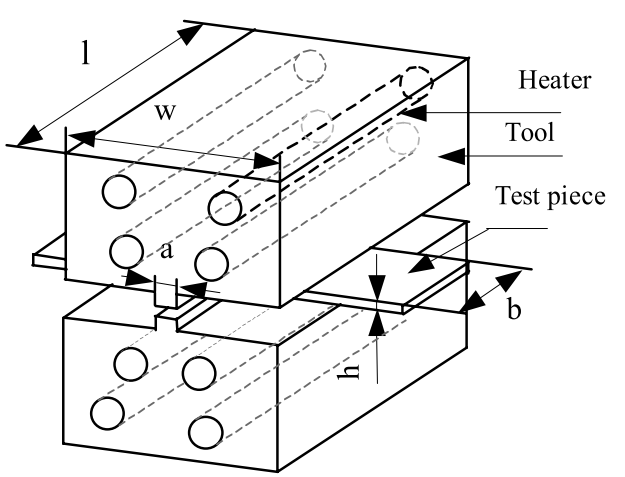

Fig. 4 Apparatus for the plane strain compression tool

Table 2 Specification of test die tool

\begin{tabular}{|c|c|}
\hline Material & SKD61 \\
\hline Size & $\mathrm{a}=8, \mathrm{~b}=50, \mathrm{~h}=2.5, \mathrm{w}=80, \mathrm{l}=80[\mathrm{~mm}]$ \\
\hline Heater & $200 \mathrm{~V}, \quad 75 \mathrm{~W} \times 8$ \\
\hline
\end{tabular}

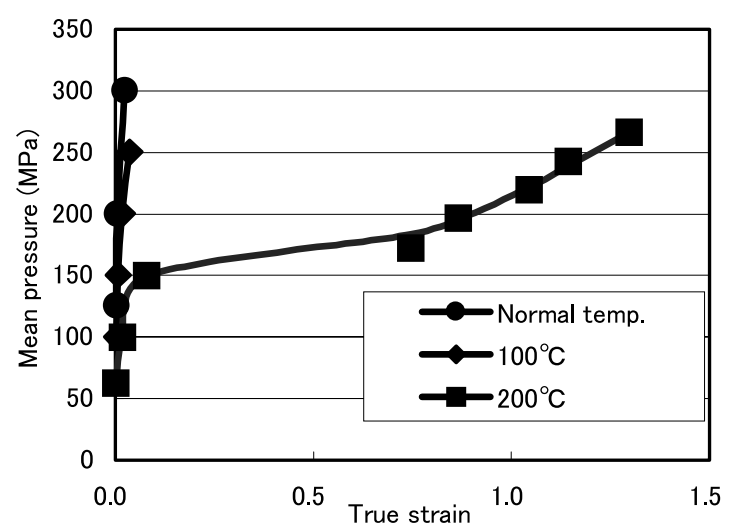

Fig. 5 Relation between mean pressure and strain in plane strain compression

With the temperature rise, the proof stress and tensile strength decrease, and elongation increases as shown in Fig. 2. It is supposed that plastic deformability is drastically improved above $200^{\circ} \mathrm{C}$. However, with the temperature rise, the test speed (strain rate) so affects on the proof stress, tensile strength and elongation that stresses becomes higher and elongation smaller.

\subsection{Plane strain compression}

In the metal forming processes, plane strain deformation has been much observed. Thus, the plane strain compression tests have been performed and the stress and strain behaviors are compared with that by the uni-axial tensile test. The dies install bar heaters embedded as shown in Fig. 4 and Table 2. The die temperature is able to be raised up to $250^{\circ} \mathrm{C}$. To neglect the friction between dies and deforming material, the grease contained Mo is employed as lubricant.

Figure 5 shows the relation between the mean pressure and true strain obtained by the plane strain compres- 


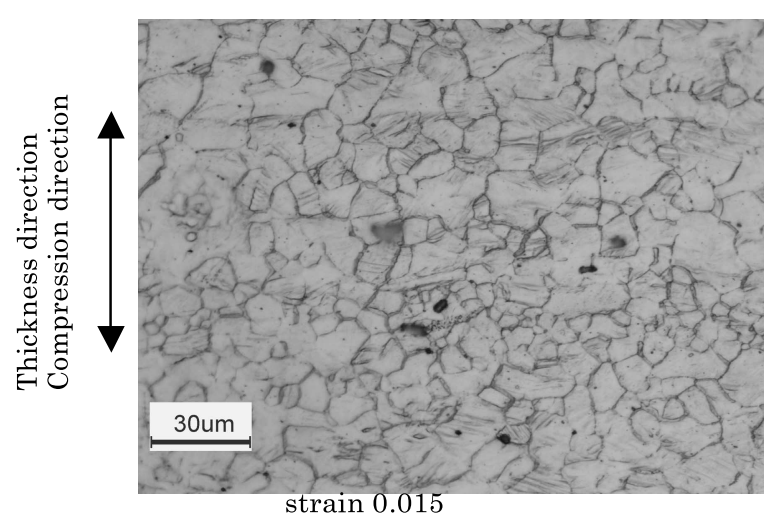

(a) Normal temp.

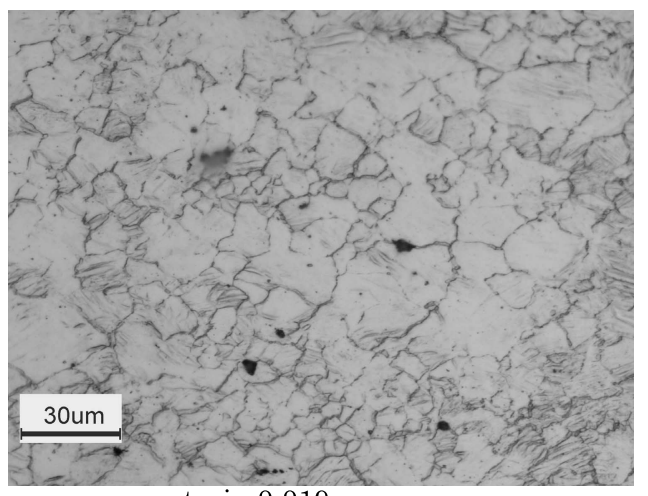

strain 0.019

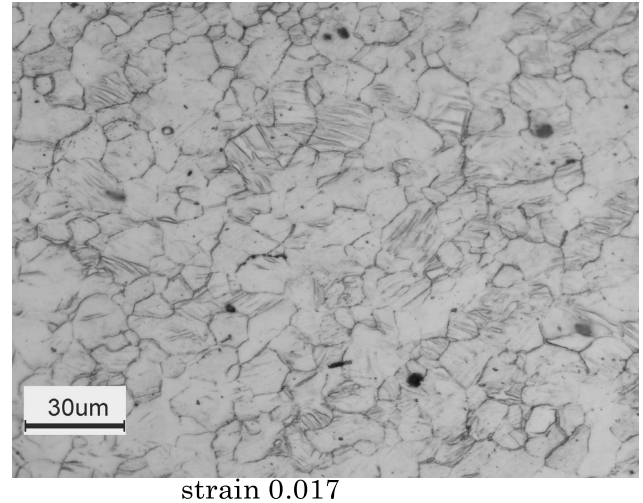

(b) $100^{\circ} \mathrm{C}$

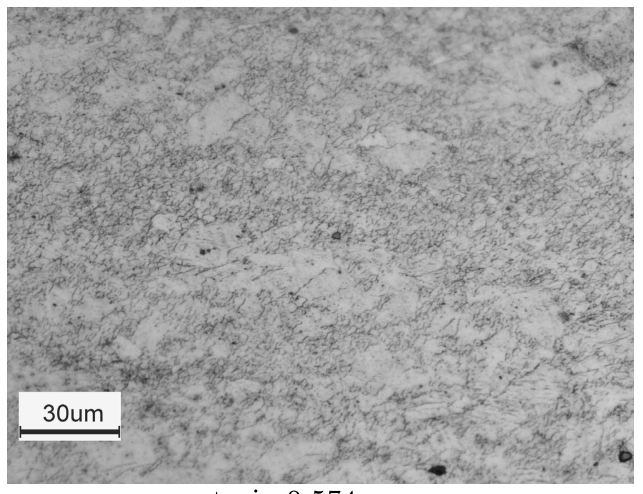

strain 0.574

(c) $200^{\circ} \mathrm{C}$

Fig. 6 Microstructures of deformed materials after plane strain compression

sion test. Below the temperature of $100^{\circ} \mathrm{C}$, the pressure rapidly increases with small strain and it shows poor deformability. However, at $200^{\circ} \mathrm{C}$, the material shows good deformability with smaller pressure, so that large compressive strain as more than 1.3 can be obtained without failure. Figure 6 shows the microstructures of deformed materials after the compression at each temperatures and strains. In the normal temperature and $100^{\circ} \mathrm{C}$, twin deformation in a fine crystal may be observed, but at $200^{\circ} \mathrm{C}$, grain growth has occurred due to dynamic crystal recovery or dynamic re-crystallization during compression, which causes good deformability.

Figure 7 shows comparison of the equivalent stressequivalent plastic strain curves in the tension and the plane strain compression. In the normal temperature and $100^{\circ} \mathrm{C}$, elongation in the tension is a little larger than that in the compression, but at $200^{\circ} \mathrm{C}$, the result in the compression shows larger elongation. In small strain at the beginning of deformation, yield stress in the compression is smaller. However, as strain increases, yield stress becomes larger than that in the tension.

Figure 8 shows comparison of microstructures of deformed materials between the tension and the compression at the plastic strain of 0.02. Twin deformation in the compression is more observed than that in the tension, which

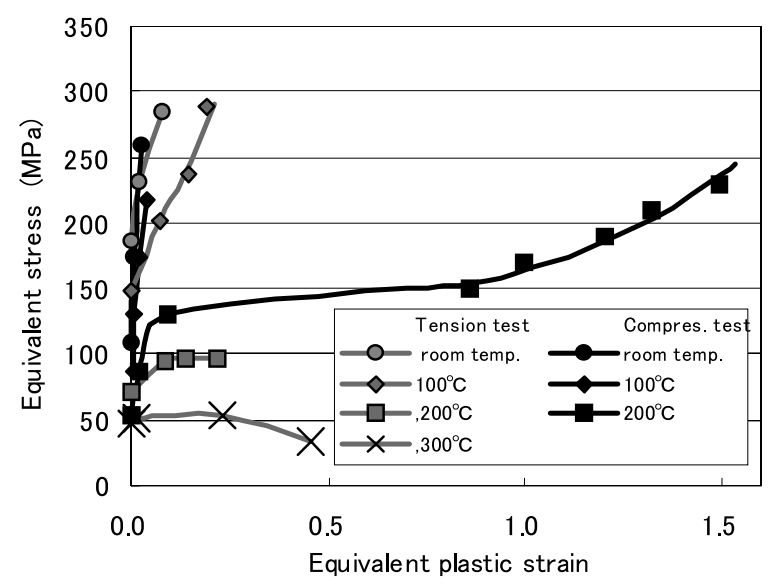

Fig. 7 Equivalent stress-equivalent plastic strain curve in tension and plane strain compression

results in smaller yield stress at the beginning of deformation in the compression.

\section{Plane Strain Compression}

To assure the effects of friction between die and deforming material on plastic deformation behaviors, the plane strain compressions with some lubricants have been performed. 

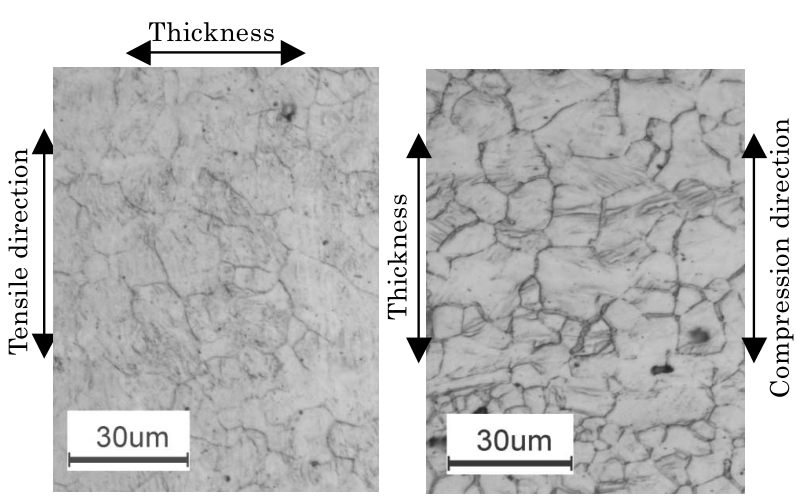

Fig. 8 Microstructures of deformed sheets at the plastic strain of 0.02

Table 3 Properties of lubricants

\begin{tabular}{|l|c|c|}
\hline & $\begin{array}{c}\text { Gravity } \\
\left(\mathrm{g} / \mathrm{cm}^{3} \text { at } 15^{\circ} \mathrm{C}\right)\end{array}$ & $\begin{array}{c}\text { Viscosity } \\
\left(\mathrm{mm}^{2} / \mathrm{s} \text { at } 40^{\circ} \mathrm{C}\right)\end{array}$ \\
\hline Mineral oil & 0.87 & 90.5 \\
\hline $\begin{array}{l}\text { Synthetic } \\
\text { ester A }\end{array}$ & 0.86 & 6.70 \\
\hline $\begin{array}{l}\text { Synthetic } \\
\text { ester C }\end{array}$ & 0.90 & 1110.0 \\
\hline Dry (no lub.) & - & - \\
\hline
\end{tabular}

\subsection{Experiment condition}

In the experiment, material to be deformed and compression tool are employed as same as mentioned above. Three kinds of lubricants are employed as shown in Table 3. Two synthetic esters with different viscosities are prepared in the experiment to make clear the effect of lubricant on deformability. Mineral oil is normally used in sheet rolling of $\mathrm{Mg}$ alloys, and synthetic esters are employed in aluminum and steel sheet rolling. Temperatures of both material and tool dies are set from room temperature to $250^{\circ} \mathrm{C}$ in the experiments.

\subsection{Experiment results}

Figure 9 shows the relation between the mean compressive pressure and true strain in each experiment temperature. In the normal temperature and $100^{\circ} \mathrm{C}$, lubricant shows a little effect on the deformability, and at $200^{\circ} \mathrm{C}$, lubricant remarkably improves the deformability. Especially, synthetic esters $\mathrm{A}$ and $\mathrm{C}$ provide larger plastic strain with small compressive pressure.

However, when the temperature rises to $250^{\circ} \mathrm{C}$, lubricants have no effect on deformability, and the mean pressure are coincide with that in dry friction. It may be caused by vaporization of lubricants around $250^{\circ} \mathrm{C}$.

Figure 10 shows microstructures of deformed materials in the plane strain compression at the temperature of $200^{\circ} \mathrm{C}$, comparing between dry (without lubricant) and lubricated (with ester A) frictions. The material compressed with dry friction shows less uniform microstructure in the thickness direction than that of the material with lubricant. The structure of the deformed material with dry friction

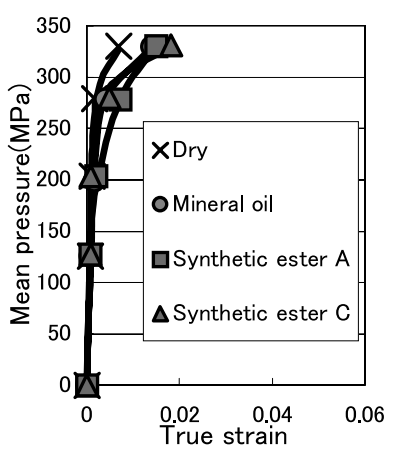

(a) Room temp.

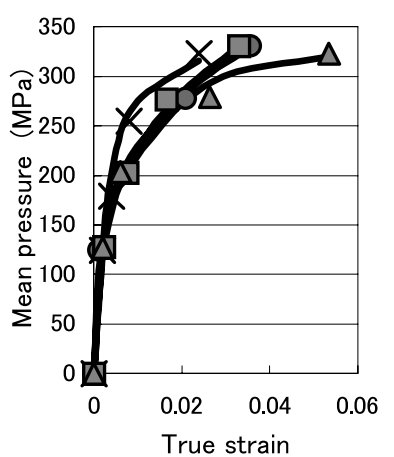

(b) $100^{\circ} \mathrm{C}$

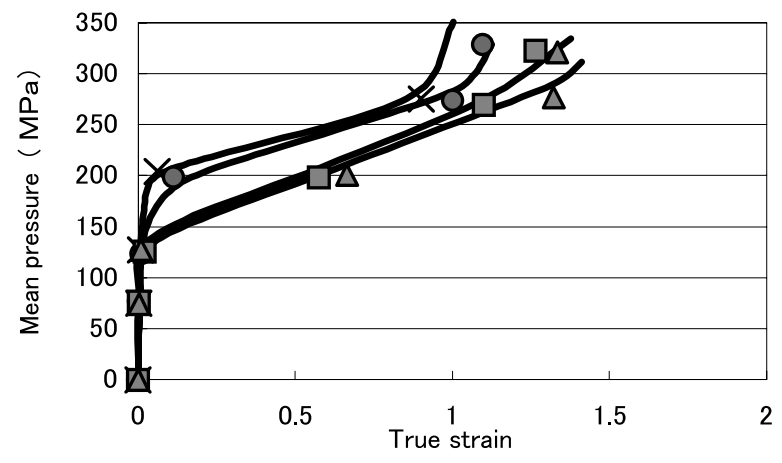

(c) $200^{\circ} \mathrm{C}$

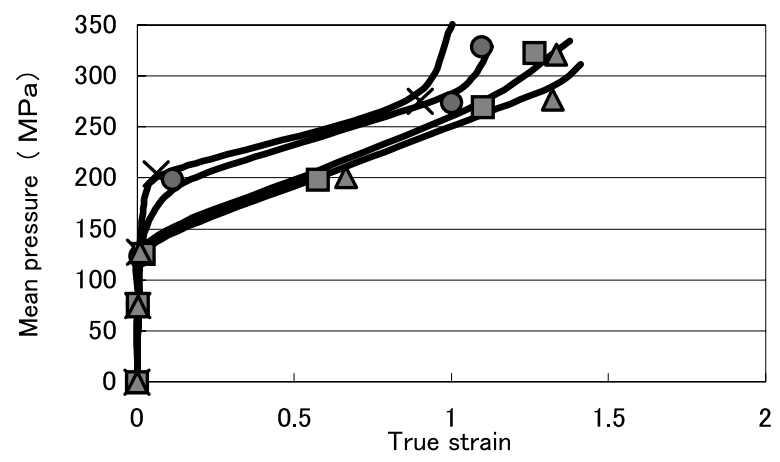

(d) $250^{\circ} \mathrm{C}$

Fig. 9 Effect of lubricants on mean pressure and strain relations in plane strain compression

has larger grain around the surface, and fine and coarse grains coexist at the center in the thickness. The structure of the material with dry friction is larger than that with lubricant at the surface contacting with die, due to the socalled un-deformed dead metal.

\section{Discussion}

Effect of friction between die and deforming material on plastic deformation behaviors of the material in the plane strain compression has been discussed. Stress and strain in the deforming materials are analyzed by the elastic-plastic FEM employing the ANSYS code. The equivalent stress and equivalent plastic strain relation in the compression analysis is employed the relation as shown in Fig. 7. 

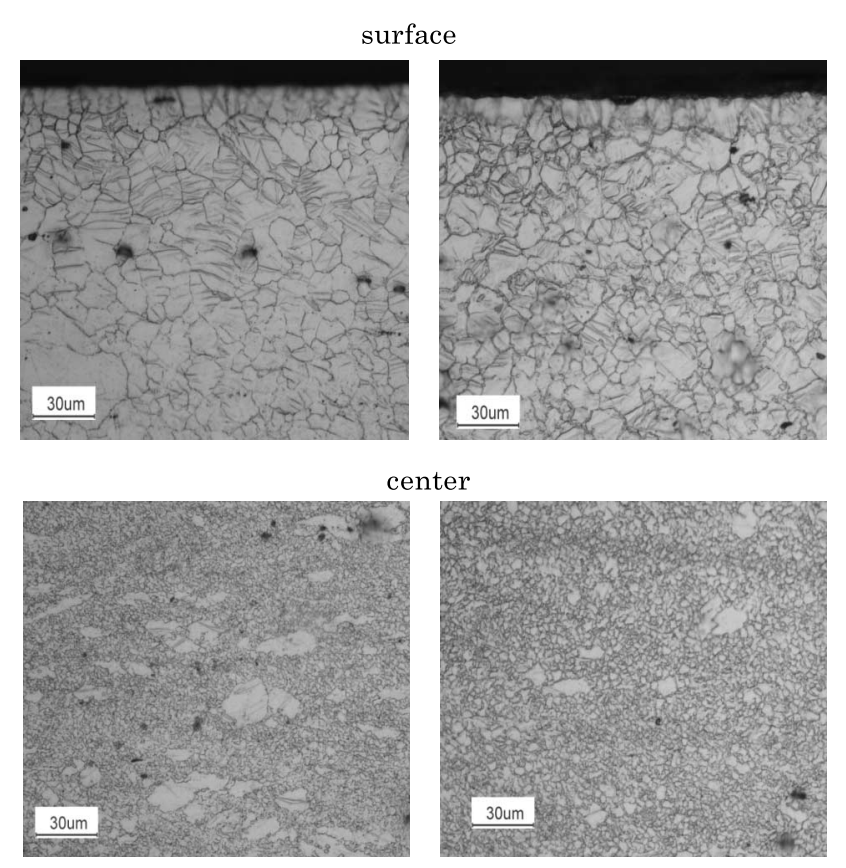

Dry

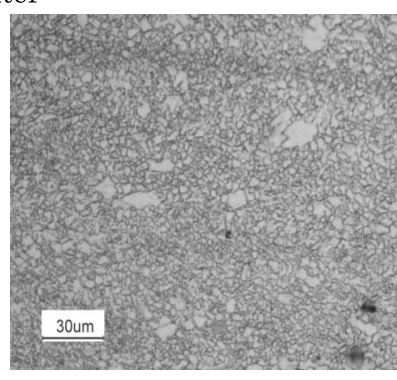

Lubricant A

Fig. 10 Microstructures of deformed materials in plane strain compression at temperature $200^{\circ} \mathrm{C}$ comparing between dry (without lubricant) and lubricated (with ester A)

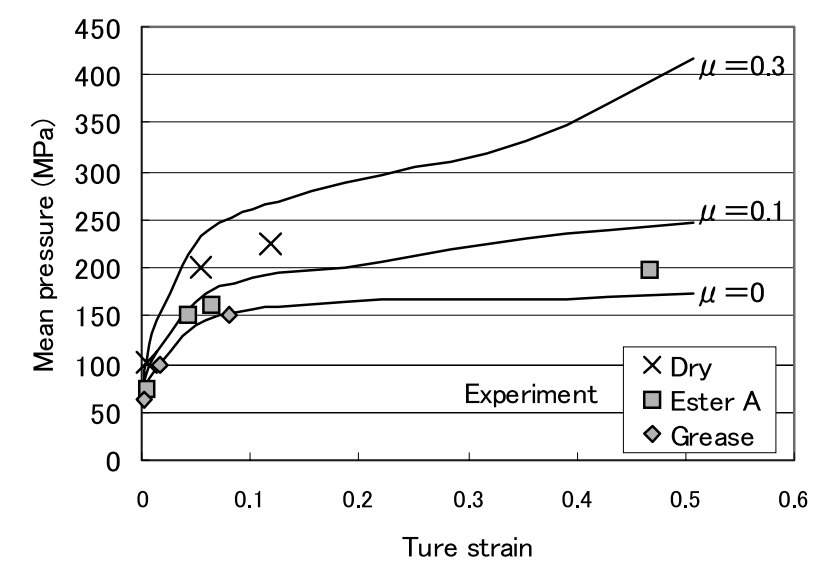

Fig. 11 Effect of friction coefficient on mean compressive pressure and true strain obtained by EP-FEM and by experiment of plane strain compression

Figure 11 shows relation of the mean compressive pressure and true strain according to friction coefficients comparing between that calculated by the elastic-plastic finite element method and that obtained by the experiment at the temperature of $200^{\circ} \mathrm{C}$. The relation without lubrication (dry) roughly coincides with $\mu=0.3$, and the relation with ester A coincides with $\mu=0.1$ respectively.

Figure 12 shows the equivalent plastic strain distributions calculated by the elastic plastic finite element analysis employing the ANSYS code. The strain distribution with dry friction supposing friction coefficient of $\mu=0.3$ is less uniform in the thickness direction than that with lubrication supposing $\mu=0.1$. Larger equivalent plastic strain
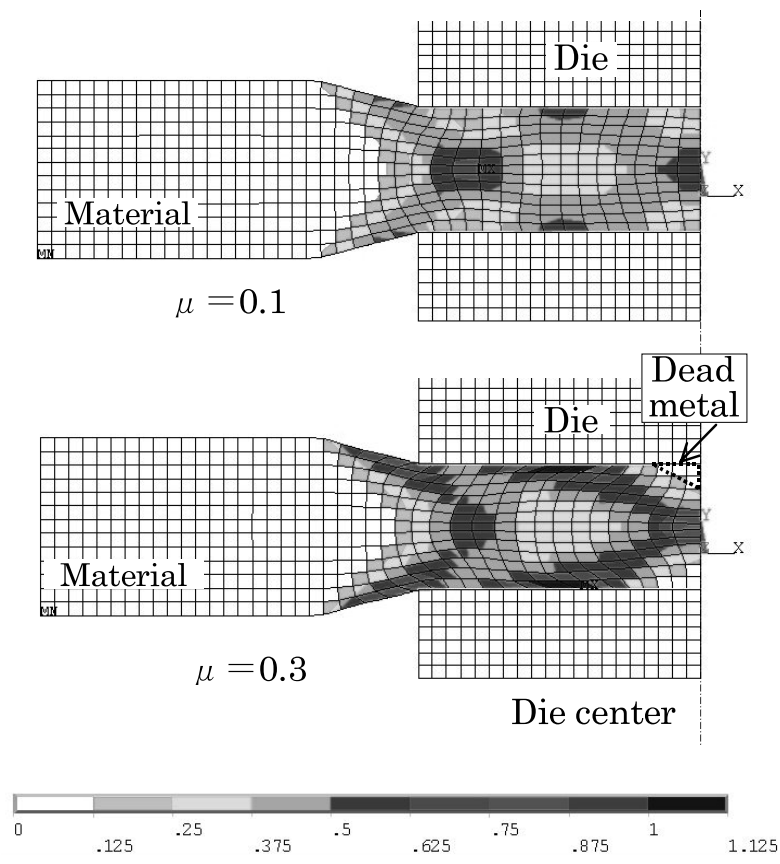

Fig. 12 Equivalent plastic strain distributions calculated by EPFEM (reduction=30\%)

arises at the center of material in thickness. The surface of deforming materials at the center of die have small strain, and the un-deformed dead metal is observed at directly under the center of die in the case of $\mu=0.3$. The difference of uniformity of strain distributions between frictions causes to the difference of the microstructure in the thickness direction as shown in Fig. 10.

\section{Conclusion}

Stress and strain behaviors of Mg alloy AZ31 hotrolled sheet by the uni-axial tension and by the plane strain compression tests in the temperature from $20^{\circ} \mathrm{C}$ to $250^{\circ} \mathrm{C}$ have been discussed. The plane strain compression tests with some lubricants have been performed. Then, the effects of friction between die and deforming material on plastic deformation behaviors are investigated by the compression tests and by the elastic-plastic finite element analysis. The results obtained are as follows;

(1) The material shows good deformability above the temperature of $200^{\circ} \mathrm{C}$, so that large compressive strain may be obtained without failure.

(2) In small plastic strain region, the yield stress in compression is smaller, and with strain increase, the yield stress becomes larger than that in tension.

(3) At $200^{\circ} \mathrm{C}$, lubricants remarkably improve deformability of the material. However, as the temperature arises to $250^{\circ} \mathrm{C}$, lubricants have no effect on deformability due to their vaporization.

(4) The strain distribution with dry friction is less uniform in the thickness direction than that with lubrication. Thus, the material compressed with dry friction 
shows less uniform microstructure in the thickness direction than that of the material compressed with lubricant.

\section{References}

(1) The Japan Magnesium Association, Plastic Deformation and Formability for $\mathrm{Mg}$ and Its Alloys, Handbook of Advanced Magnesium Technology, (in Japanese), Edited by Kojima, Y., (2000), pp.105-119.

( 2 ) Sato, J., Study on Forming Process and Applicability of Magnesium Alloy (II), Repts. of Research. Inst. Industrial Products Tech., Gifu Pref. Gov., (in Japanese), No.3 (2002).

( 3 ) Ohguchi, S., Sugamata, Y., Kaneko, J. and Kubota, M., Effect of Rolling Conditions on Properties of AZ31 Magnesium Alloy Sheets Prepared by Heated Roll Mill, Proc. 54th JSTP, (in Japanese), (2003), pp.89-90.
( 4 ) Ataka, M., Sakurai, I., Yanagimoto, J. and Yanagida, A., Edge Cracks Caused by Cold Rolling of the $\mathrm{Mg}$ Alloy Sheet, Proc. 54th JSTP, (in Japanese), (2003), pp.103-104.

( 5 ) Saiki, H., Gen, R. and Marumo, Y., Evaluation of Flow Stress and Tribo-Characteristics of Mg Alloy AZ31 in Hot Working Process, Proc. 54th JSTP, (in Japanese), (2003), pp.151-152.

( 6 ) Yarita, I., Okayama, Y. and Naoi, T., Stress-Strain Behavior of Magnesium Alloy AZ31 Sheet in Tension and Plane Strain Compression Tests, Proc. M\&P2003, (in Japanese), (2003), pp.307-308.

( 7 ) Naoi, T., Yarita, I., Hashizume, T. and Okayama, Y., Stress-Strain Behavior of Magnesium Alloy AZ31 Sheet in Tension and Compression Tests, Proc. M\&P2004, (in Japanese), (2004), pp.405-406. 